\title{
SCIENCE
}

\section{Molecular Borromean Rings}

\author{
Kelly S. Chichak, ${ }^{1}$ Stuart J. Cantrill, ${ }^{1}$ Anthony R. Pease, ${ }^{1}$ \\ Sheng-Hsien Chiu, ${ }^{1}$ Gareth W. V. Cave, ${ }^{2}$ Jerry L. Atwood, ${ }^{2}$
}

J. Fraser Stoddart ${ }^{1 *}$

The realization of the Borromean link in a wholly synthetic molecular form has long been perceived as a Gordian knot. Our reporting here of the nearquantitative self-assembly of this topologically achiral link from 18 components by the template-directed coordination around six zinc(II) ions of six bidentate and six tridentate ligands, resulting in the formation in alcoholic solution of 12 imine bonds, cuts this Gordian knot. The resulting Borromean ring compound extols the virtue of employing, in concert, coordination, supramolecular, and dynamic covalent chemistry to aid and abet the rapid construction of complex nanosystems by multiple cooperative self-assembly processes.

${ }^{1}$ Department of Chemistry and Biochemistry and the California NanoSystems Institute, University of California, Los Angeles, 405 Hilgard Avenue, Los Angeles, CA 90095, USA. ${ }^{2}$ Department of Chemistry, University of Missouri-Columbia, MO 65211, USA.

*To whom correspondence should be addressed. E-Mail: stoddart@chem.ucla.edu

One sentence summary - The realization of the Borromean link as a molecular compound has been accomplished synthetically by exploiting the virtues of coordination, supramolecular, and dynamic covalent chemistry in a cooperative manner. 
An object of particular interest in knot theory is known as the Borromean Rings (BRs). It occurs in low-dimensional topology and is comprised (Fig. 1A) of three interlocked rings such that scission of any one ring leads to the other two falling apart. Although this unique symbol can be traced (1) back to early Christian iconography and Norse mythology, its proliferation on crests and statues commissioned by the Borromeo family in fifteenth century Tuscany sealed its etymological fate. In addition to its having made cultural inroads into art and theology and heraldry, the last century witnessed its emergence on the scientific horizon of particle physics (2) and magnetism (3), as well as in the formidable challenge $(4,5)$ it presents to synthetic chemists in search of molecular expression. In the wake of Wasserman's first synthesis (6) of a compound-a [2]catenane-in which the molecules have two interlocked rings, the field of molecular topology has blossomed (7-9). Although more elaborate examples in chemical topology $(10,11)$ and topological stereochemistry $(12,13)$ have emerged $(14$, $15)$ in the shape of molecular knots, as well as catenanes, the BRs, in a wholly synthetic form, have proved to be elusive (16-19).

Conceptually, there are two extreme synthetic strategies for the construction of molecular Borromean links - (i) a stepwise synthesis wherein the three rings are slotted into place by successive templation (20) one at a time, and (ii) a strict self-assembly protocol $(21,22)$ which brings the components of the three rings together under comprehensive template-directed control (20) in one fell swoop. A ring-by-ring (23-25) approach, that is predominantly kinetically controlled, courts the danger of being burdened by undesirable side-reactions, particularly in the formation of the third and final ring of the Borromean links where the geometrical demands associated with both noncovalent and covalent bond formation are likely to be not inconsiderable. By contrast, an all-in-one strategy, which combines the virtues of reversibility, proofreading, and error-checking we associate with supramolecular (26) and dynamic covalent (27) chemistry with the geometrical precision afforded by coordination chemistry (28-30), allows the synthetic chemist to take up the gauntlet of assembling molecular BRs in the knowledge that thermodynamic control can be an efficient supplier of a complex product (27). Such a paradigm requires that each individual piece in the molecular self-assembly process is programmed so that the multiple molecular recognition between the pieces is optimized in a highly cooperative manner in the desired product. In our bid to self-assemble a BR compound, it was essential to ensure that cooperativity between $\pi-\pi$ stacking interactions and coordination geometries was honed up to perfection. This crucial design element was satisfied 
computationally by molecular modeling. The manner in which the computer-aided design of the $\mathbf{B R}^{12+}$ dodecacation led directly to its synthesis in very high yields is rare in our experience.

The successful construction of a BR compound from individual pieces relies on the precise control of the six cross-over points that can be identified in the Venn representation (Fig. 1A) where the like signs of the three outer nodes are opposite to those of the three inner nodes. Although these nodes define the topology of the final assembly, in order to conceive retrosynthetic disconnections, it is advantageous to reorient the three interlocked rings to be mutually perpendicular in Cartesian space as depicted in the orthogonal representation (Fig. 1B). With reference to any one of the three identical rings, the sequence of four alternating nodes $(+/-/+/-)$ can manifest itself in the form of exo/endo/exo/endo binding sites in a wholly cross-complementary fashion. In a chemical context (Fig. 1C), transition metals can be embedded into these binding sites, thus ensuring complete three-dimensional control at all six such sites through a judicious choice of coordination geometry. Specifically, differentiation of the exo and endo binding sites at each of six ring crossings can be established through the union (Fig. 1D) of bidentate and tridentate ligands around a five-coordinate metal ion. The requirements for flexibility and reversibility in the coordination spheres were met by employing kinetically labile zinc(II) ions, each bound preferentially to one exo bipyridyl ligand and one endo bis-Schiff base ligand. Ligands of this latter class have a long history (28) of forming macrocycles in the presence of metal ion templates. It seemed propitious, therefore, to incorporate endo tridentate ligands, as a result of dynamic imine bond formation (27) between 2,6-diformylpyridine (DFP) and a diamine (DAB) harboring the exo bidentate ligands in a [2+2] macrocyclization (Fig. 1E). Whereas in the absence of a metal-ion template, a complex mixture of polymeric and macrocyclic products is the likely outcome, introduction of zinc(II) ions is expected to template the formation of molecular BRs with maximal site occupancy (31) being honored. Molecular modeling (32) of the Borromean links, constructed from the appropriately interlocked arrangement of three [2+2] macrocycles revealed only two molecular trinities stabilized by combinations of $12 \pi-\pi$ stacking interactions and 30 dative bonds - one with $C_{\mathrm{i}}\left(=S_{2}\right)$ symmetry and the other, shown in (Fig. 1E), with $S_{6}$ symmetry.

Initial ${ }^{1} \mathrm{H}$ NMR spectroscopic investigations, conducted in a $\mathrm{CD}_{3} \mathrm{OD}$ solution containing equimolar amounts of DFP and DAB- $\mathrm{H}_{4} \cdot 4$ TFA revealed that little or no reaction occurs 
at room temperature over the course of several hours. Upon the addition of an equivalent of $\mathrm{Zn}(\mathrm{OAc})_{2}$ to the NMR tube, a profound change occurs in the spectrum within minutes, indicating that a reaction is occurring. In order to expedite the selfassembly process, the reaction mixture was heated under reflux for three days. Periodic monitoring of the ${ }^{1} \mathrm{H}$ NMR spectrum revealed that equilibrium is reached after two days, affording predominantly $(90 \%)$ one highly symmetric entity. In order to isolate sufficient quantities of the major product for characterization, the reaction was repeated on a preparative scale, resulting in a pale yellow powder which was crystallized from $\mathrm{MeOH} / \mathrm{Et}_{2} \mathrm{O}$ to yield a pure crystalline sample. ESI-MS Analysis of this sample reveals three major peaks at $m / z 1465,1070$, and 834, corresponding to [M-3TFA $]^{3+},[M-$ $4 \mathrm{TFA}]^{4+}$ and $[M-5 \mathrm{TFA}]^{5+}$, respectively, a situation which was consistent with the proposed Borromean ring compound BR 12 TFA.

Comparison of the ${ }^{1} \mathrm{H}$ NMR spectrum (Fig $2 \mathrm{~B}$ ) of this crystalline material with that (Fig. $2 \mathrm{~A}$ ) of DAB- $\mathrm{H}_{4}$ 4TFA (both spectra recorded in $\mathrm{CD}_{3} \mathrm{OD}$ ) reveals significant changes in the chemical shifts for the aromatic protons of the DAB fragment: specifically the resonances for H-e, H-f, H-g, and H-i are all shifted upfield by as much as from 0.1 to $0.9 \mathrm{ppm}$, indicating that $\pi-\pi$ stacking interactions, heralded by the computational investigations carried out on the molecular Borromean ring compound $\mathbf{B R}^{12+}$. The averaged molecular symmetry $\left(T_{h}\right)$ of this compound, which is fluxional on the ${ }^{1} \mathrm{H}$ NMR timescale at $+50{ }^{\circ} \mathrm{C}$, is such that we would only expect to see ${ }^{1} \mathrm{H}$ NMR signals for one quadrant of one component macrocycle, since all three rings are equivalent. Inspection of the ${ }^{1} \mathrm{H}$ NMR spectrum shown in Fig. 2B reveals eight of the anticipated nine signals centered on $\delta 8.89$ (H-c), $8.62(\mathrm{H}-\mathrm{a}), 8.31$ (H-b), 7.97 (H-i), 6.74/6.68 (H-e/f), $6.50(\mathrm{H}-\mathrm{g})$, and $4.84(\mathrm{H}-\mathrm{d})$. It is significant that the signal for $\mathrm{H}-\mathrm{g}$ on the bipyridyl ligand is broad while that for the vicinal $\mathrm{H}$-h proton has become merged into the base line between $\delta 7$ and 8 . A spectrum recorded at $+50{ }^{\circ} \mathrm{C}$ indicates that the signal for $\mathrm{H}-\mathrm{g}$ becomes much sharper while that for $\mathrm{H}-\mathrm{h}$ emerges out of the baseline and resonates as a broad singlet, centered on $\delta 7.90$. This temperature-dependent behavior suggests that a conformational change is occurring within the $\mathbf{B R}^{12+}$ dodecacation that is of the order of the NMR timescale at room temperature.

The X-ray crystallographic analysis (33) of BR -12TFA reveals a molecular structure (Fig. $3 \mathrm{~A}-\mathrm{E}$ ) with $S_{6}$ symmetry wherein the three rings have the topology of a Borromean link. Each of the three equivalent rings adopt a chair-like conformation and consequently each $\mathbf{B R}^{12+}$ dodecacation can be symmetry related from half of one of the rings, which is 
$24.5 \AA$ long from the tip of one pyridyl residue to the tip of the other. Molecular recognition is manifest in a mutually compatible manner. The three equivalent rings are held together by six $\mathrm{Zn}$ (II) ions positioned $12.74 \AA$ apart. They are each coordinated in a slightly distorted octahedral geometry to five nitrogen atoms with the sixth coordination site occupied by an oxygen atom belonging to a TFA- anion with a disordered trifluoromethyl group. The six equivalent bipyridyl ligands are sandwiched unsymmetrically between six pairs of phenolic rings, such that the $\pi-\pi$ stacking distance is $3.61 \AA$ in one direction and $3.66 \AA$ in the other. The $\mathbf{B R}^{12+}$ dodecacation contains an inner chamber of volume $250 \AA^{3}$ lined with 12 oxygen atoms which are oriented in the form of a cuboctahedron array toward the center of the chamber which contains species that give rise to non-resolved and diffuse electron density. At a supramolecular level, the $\mathbf{B R}^{12+}$ dodecactions are arranged (Fig. 3E) in hexagonal arrays with close (3.31 $\AA$ ) intermolecular $\pi-\pi$ stacking interactions between pairs of pyridyl rings in adjacent dodecacations which form (Fig. 3F) columnar arrays in the orthogonal $c$-direction that are stabilized by six $[\mathrm{C}-\mathrm{H} \cdots \mathrm{O}=\mathrm{C}]$ interactions between each $\mathbf{B R}^{12+}$ dodecacation, the centers of which are $16.3 \AA$ apart. The six cylindrical channels which surround each column have a diameter of $4.2 \AA$ and are filled with $\left[\mathrm{ZnTFA}_{4}\right]^{2-}$ counterions.

When the self-assembly process was repeated in 95\% EtOH, we noted (Fig. 4) the appearance of additional peaks in the ESI mass spectrum at $\mathrm{m} / \mathrm{z} 1563$ and 1143 corresponding to $[M-3 \mathrm{TFA}]^{3+}$ and $[M-4 \mathrm{TFA}]^{4+}$, respectively - a situation which can be explained if an additional Zn 2TFA is associated with BR 12TFA. We propose that the central electron-rich cavity, decorated with 12 donor oxygen atoms and so qualitatively reminiscent of Cram's spherands (34), hosts the seventh Zn(II) ion. This hypothesis is supported by an ${ }^{1} \mathrm{H}$ NMR spectrum (Fig. 2C) which shows an additional set of signals, some of which correspond to protons (H-c/c', H-b/ $b^{\prime}$, and $\left.\mathrm{H}-\mathrm{a} / \mathrm{a}^{\prime}\right)$ on the periphery of the molecule and overlap with those for BR 12TFA, for another highly symmetrical species which we propose is $\mathbf{Z n @ B R} \cdot 14 T F A$, i.e., a seventh $\mathrm{Zn}(\mathrm{II})$ ion occupies the central electron-rich cavity of $\mathbf{B R}^{12+}$. Of further significance is the fact that resonances corresponding to the protons $\mathrm{H}-\mathrm{i}^{\prime}$ and $\mathrm{H}-\mathrm{g}^{\prime}$, located much closer to the core of the molecule, are influenced most in their chemical shifts by the incarcerated guest.

The ability to be able to produce gram quantities of highly soluble hosts which can locate a range of different transition metals in an insulated octahedral array around an inner heteroatom-lined chamber, which can provide a welcoming home for many different guest species, conjures up numerous ideas on how BR compounds could be 
exploited as highly organized nano-clusters in a materials setting - e.g., spintronics (35) or in a biological context, e.g., medical imaging (36). Aside from all the practicalities that surround forging new technologies-which are not unimportant-any mathematical, physical, or biological science associated with BR compounds has to impinge in an intellectually stimulating way, not only on a wealth of fundamental concepts-including symmetry, topology, and chirality-but also on art and symbolism, together with geography and history, as they have evolved around human culture since the beginning of civilization.

\section{References and Notes}

1. P. Cromwell, E. Beltrami, M. Rampichini, Mathematical Intelligencer 20, 53 (1998).

2. S. M. Austin, G. F. Bertsch, Sci. Am. 272, 90 (1995).

3. A. Ruzmaikin, P. Akhmetiev, Phys. Plasmas 1, 331 (1994).

4. C. Liang, K. Mislow, J. Math. Chem. 16, 27 (1994).

5. K. Mislow, Topics Stereochem. 22, 1 (1999).

6. E. Wasserman, J. Am. Chem. Soc. 82, 4433 (1960).

7. H. L. Frisch, E. Wasserman, J. Am. Chem. Soc. 83, 3789 (1961).

8. S. J. Tauber, J. Res. Nat. Bur. Stand., Sect. A 67A, 591 (1963).

9. G. Schill, Catenanes, Rotaxanes and Knots (Academic, New York, 1971).

10. N. van Gulick, New J. Chem. 17, 619 (1993).

11. J. Simon, Proc. Symp. Appl. Math. 45, 97 (1992).

12. V. I. Sokolov, Russ. Chem. Revs. 42, 452 (1973).

13. D. M. Walba, Tetrahedron 41, 3161 (1985).

14. D. B. Amabilino, J. F. Stoddart, Chem. Rev. 95, 2725 (1995).

15. J.-P. Sauvage, C. Dietrich-Buchecker, Eds., Molecular Catenanes, Rotaxanes and Knots (Wiley-VCH, Weinheim, 1999).

16. To our knowledge, the only case which is known of molecular BRs was assembled from single-stranded DNA and is comprised of three individual rings of 196, 206, and 216 nucleosides. See: C. Mao, W. Sun, N. C. Seeman, Nature 386, 137 (1997).

17. For a metallic microstructure possessing the BR topology, see: $\mathrm{H}$. Wu, S. Brittain, J. Anderson, B. Grzybowski, S. Whitesides, G. M. Whitesides, J. Am. Chem. Soc. 122, $12691(2000)$. 
18. Examples of Borromean links within 2D and 3D arrays have been identified retroactively in certain coordination polymers. See: L. Carlucci, G. Ciani, D. M. Proserpio, CrystEngComm. 5, 269 (2003).

19. For examples of hexanuclear cage complexes with topological structures reminiscent of BRs, see: O. V. Dolomanov, A. J. Blake, N. R. Champness, M. Schröder, C. Wilson, Chem. Commun. 682 (2003).

20. F. Diederich, P. J. Stang, Eds., Templated Organic Synthesis (Wiley-VCH, Weinheim, 2000).

21. J. S. Lindsey, New J. Chem. 15, 153 (1991).

22. L. R. MacGillivray, J. L. Atwood, Nature 389, 469 (1997).

23. S.-H. Chiu, A. R. Pease, J. F. Stoddart, A. J. P. White, D. J. Williams, Angew. Chem. Int. Ed. 41, 270 (2002).

24. M. Schmittel, A. Ganz, D. Fenske, Org. Lett. 4, 2289 (2002).

25. J. C. Loren, M. Yoshizawa, R. F. Haldimann, A. Linden, J. S. Siegel, Angew. Chem. Int. Ed. 42, 5702 (2003).

26. J.-M. Lehn, Supramolecular Chemistry (VCH, Weinheim, 1995).

27. S. J. Rowan, S. J. Cantrill, G. R. L. Cousins, J. K. M. Sanders, J. F. Stoddart, Angew. Chem. Int. Ed. 6, 898 (2002).

28. T. J. Hubin, A. G. Kolchinski, A. L. Vance, D. L. Busch, Adv. Supramol. Chem. 5, 237 (1999).

29. M.-J. Blanco, J.-C. Chambron, M. C. Jiménez, J.-P. Sauvage, Topics Stereochem. 23, 125 (2003).

30. D. A. Leigh, P. J. Lusby, S. J. Teat, A. J. Wilson, J. K. Y. Wong, Angew. Chem. Int. Ed. 40, 1538 (2001).

31. R. Krämer, J.-M. Lehn, A. Marquis-Rigault, Proc. Natl. Acad. Sci. USA 90, 5394 (1993).

32. The $\mathbf{B R}^{12+}$ dodecacation was constructed within the input mode of Macromodel 4.0 by aligning the three identical [2+2] macrocycles and six $\mathrm{Zn}$ (II) ions in an orthogonal arrangement which was subjected to energy minimization employing the Polak-Ribière Conjugate Gradient (PRCG) method and AMBER* forcefield.

33. Single crystals suitable for $\mathrm{X}$-ray crystallographic analysis were grown by vapor diffusion of $n-\mathrm{Bu}_{2} \mathrm{O}$ into a $\mathrm{CF}_{3} \mathrm{CH}_{2} \mathrm{OH}$ solution of BR 12TFA. A colorless single crystal was attached with oil to a thin glass fiber. Crystal data for $\left[\left(\mathrm{C}_{62} \mathrm{H}_{46} \mathrm{~N}_{10} \mathrm{O}_{4}\right)_{3}\right.$ 
$\left.\left(\mathrm{ZnCF}_{3} \mathrm{CO}_{2}\right)_{6}\right] 3\left[\mathrm{Zn}\left(\mathrm{CF}_{3} \mathrm{CO}_{2}\right)_{4}\right], M_{\mathrm{r}}=5608.0$, trigonal, $a=b=38.937(5) \AA$ and $c=$ 32.604(8) $\AA, V=42809(13) \AA^{3}$, space group $R_{3}^{-} \mathrm{c}, Z=36, \rho_{\text {calc }}=1.305 \mathrm{~g} \mathrm{~cm}^{-3}$, $\lambda\left(\mathrm{Mo}_{\mathrm{K} \alpha}\right)=0.70930 \AA, F(000)=16920, T=173(1) \mathrm{K}, 10598$ unique reflections $(2 \theta \leq$ $\left.56^{\circ}\right)$, of which 2587 were observed $\left[I_{\mathrm{o}}>2 \sigma(I)\right]$. Final R-factors: $R_{1}=0.1656, w R_{2}=$ 0.5151 for 381 parameters. Data was collected on a Bruker SMART 1000 CCD diffractometer with $\mathrm{Mo}_{\mathrm{K} \alpha}$ radiation using the $\omega$-scan mode. Data were corrected for absorption using the SADABS program and structure solution and refinement were performed using the SHELX-97 software package. All non-hydrogen atoms and non guest molecules were refined anisotropically while the hydrogen atoms were included at geometrically calculated positions, and allowed to ride on their parent atoms. Details of the X-ray structure determination are available from the Cambridge Crystallographic Data Centre (CCDC), deposition number CCDC 231701. This data can be obtained free of charge via www.ccdc.cam.ac.uk/conts/retrieving.html (or from the Cambridge Crystallographic Data Centre, 12 Union Road, Cambridge CB2 1EZ, UK; fax:(+44)1223-336-033; or deposit@ccdc.cam.ac.uk).

34. D. J. Cram, J. M. Cram, Container Molecules and their Guests, p. 20-48 in Monographs in Supramolecular Chemistry, J. F. Stoddart, Ed. (Royal Society of Chemistry, Cambridge, 1994).

35. M. Ruben, E. Breuning, J.-M. Lehn, V. Ksenofontov, F. Renz, P. Gütlich, G. B. M. Vaughan, Chem. Eur. J. 9, 4422 (2003).

36. A. E. Merbach, E. Toth, The Chemistry of Contrast Agents in Medical MRI (Wiley, Chichester, 2001).

37. Supported by an NSF grant (CHE0317170) and also two equipment grants (CHE9974928 and CHE0092036), also from the NSF. Dedicated to the memory of Norma Stoddart who helped in the editing of the manuscript before she died on January 12, 2004. 


\section{Captions to Figures}

Fig. 1. The Borromean Rings (BR) can be depicted in many ways, including a planar Venn representation (A) and a more informative orthogonal arrangement (B). At each of the six crossing points on this graph, it is possible to embed a templating feature (the silver spheres shown in C) in order to control the overall three-dimensional architecture in a molecular context. By employing transition metal ions to gather around themselves appropriate ligands in a prescribed fashion, one can envisage (D) a relatively straightforward retrosynthetic disconnection of the BRs. The retrosynthesis in chemical terms (E) anticipates the use of an endo bidentate bipyridyl ligand (DAB) and an exo tridentate ligand that is formed reversibly upon the reaction of diformylpyridine (DFP) with the aforementioned $\mathbf{D A B}$ in a [2+2]macrocyclization. Molecular modeling (E, left) confirms that three such $[2+2]$ macrocycles can be slotted together to form a highly stabilized assembly with a BR topology.

Fig. 2. The ${ }^{1} \mathrm{H}$ NMR spectra $\left(\mathrm{CD}_{3} \mathrm{OD}, 298 \mathrm{~K}\right)$ of $(\mathrm{A})$ the endo bidentate ligandcontaining starting material DAB- $\mathrm{H}_{4} \cdot 4 \mathrm{TFA}(500 \mathrm{MHz}),(\mathbf{B})$ the molecular Borromean rings BR 12TFA (600 MHz), and (C) an inseparable mixture of 'empty' and 'filled' Borromean rings, namely BR ·12TFA and Zn@BR 14TFA, respectively $(600 \mathrm{MHz})$. The letters a-i are defined for $\mathbf{B R}^{12+}$ with respect to the appropriate protons on the structural formulas shown in Fig. 1E. Primed letters represent the corresponding protons in $\mathbf{Z n} @ \mathbf{B R}^{14+}$.

Fig. 3. Different structural and superstructural representations of the $\mathbf{B R}^{12+}$ dodecacation(s) in the solid-state as deduced from X-ray crystallography carried out on single crystals of BR 12TFA. In the case of the single $\mathbf{B R}^{12+}$ dodecacation, the three equivalent macrocycles are featured, as tubular and space-filling representations, in the three primary colors - namely, green, red, and blue. The six $\mathrm{Zn}$ (II) ions are depicted in silver. (A) Tubular representation viewed down the $S_{6}$ (and collinear $C_{3}$ ) axis of $\mathbf{B R}^{12+}$. Space-filling representation of $\mathbf{A}$, showing the pore with a diameter of $2.08 \AA$ in $\mathbf{B R}^{12+}$ which leads to an inner chamber. (C) Space-filling representation of BR $^{12+}$ highlighting the mutually orthogonal arrangement of the three interlocked macrocycles adopting chair-like conformations wherein the 
distance from the tip of one pyridyl ring to the other, in any given macrocycle, is $24.5 \AA$. Multiple $\pi-\pi$ stacking interactions are evident to the extent that all six equivalent bipyridyl ligands are sandwiched between six pairs of flanking phenolic rings, such that the plane-to-plane separations are $3.61 \AA$ in one direction and $3.66 \AA$ in the other. In addition there are six [C$\mathrm{H} \cdots \pi$ ] interactions $(\mathrm{H} \cdots \pi$ distance $2.78 \AA$ ) between $\mathrm{H}-\mathrm{h}$ on all of the bipyridyl ligands and the faces of the six pyridyl rings. The coordination sphere around each of the six equivalent $\mathrm{Zn}$ (II) ions has distorted octahedral geometry, with a single TFA- anion (not shown) occupying the sixth coordination site in all cases. (D) A stick representation of $\mathbf{B R}^{12+}$ upon which are superimposed (i) a Platonic solid (i.e., the silver octahedron with its vertices defined by the six $\mathrm{Zn}$ (II) ions and having edges that are all equal to $12.74 \AA$ ), and (ii) a slightly distorted Archimedean solid (i.e., the red cuboctahedron with its vertices defined by 12 oxygen atoms that line the inner chamber of $\mathbf{B R}^{12+}$ and possesses a volume of around $\left.250 \AA^{3}\right)$. (E) Space-filling representation of the hexagonal array of six individual columnar stacks of three $\mathbf{B R}^{12+}$ dodecacations clustered around a central columnar stack of three $\mathbf{B R}^{12+}$ dodecacations viewed down the $c$-direction of the crystal lattice, showing the TFA- anions (red and blue) coordinated to the $\mathrm{Zn}(\mathrm{II})$ ions. Neighboring $\mathbf{B R}^{12+}$ dodecacations are held together by intermolecular $\pi-\pi$ stacking interactions (3.31 $\AA$ ) between matching pairs of pyridyl rings. The small channels that run through the center of the superstructure are separated by $22.5 \AA$ and the large channels, which are $4.2 \AA$ in diameter, and are filled by $\mathrm{Zn}(\mathrm{II})$-coordinated TFA- anions (not shown), are separated from each other by $13.0 \AA$ A. (F) Space-filling representation of three interdigitated $\mathbf{B R}^{12+}$ dodecacations present in superstructural columns that run through the crystal in the c-direction. Each $\mathbf{B R}^{12+}$ (e.g., green) in the columnar array is linked above (i.e., purple) and below (i.e., blue) itself by six $[\mathrm{C}-\mathrm{H} \cdots \mathrm{O}=\mathrm{C}]$ hydrogen bonds (with a $[\mathrm{H} \cdots \mathrm{O}]$ distance of $2.52 \AA$ ), which arise from an interaction between $\mathrm{H}-\mathrm{g}$ in one $\mathbf{B R}^{12+}$ and the carbonyl oxygen atom of a $\mathrm{Zn}(\mathrm{II})$-bound TFA- ${ }^{-}$anion in the neighboring $\mathbf{B R}^{12+}$. The distance within the columns between the centers of repeating $\mathbf{B R}^{12+}$ dodecacations is $16.3 \AA$.

Fig. 4. The ESI mass spectrum (A) of a mixture of BR 12TFA and Zn@BR 14 TFA, (B) the expanded isotopic distribution pattern for $[M-4 \mathrm{TFA}]^{4+}$, which correlates well with the calculated distribution shown in C. 
Fig. 1

A

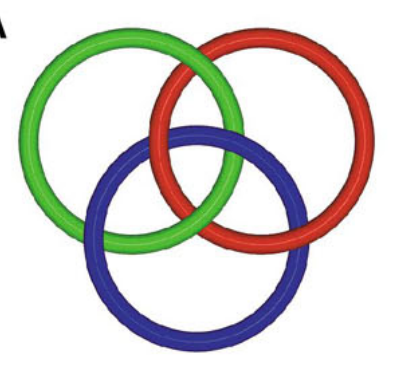

B

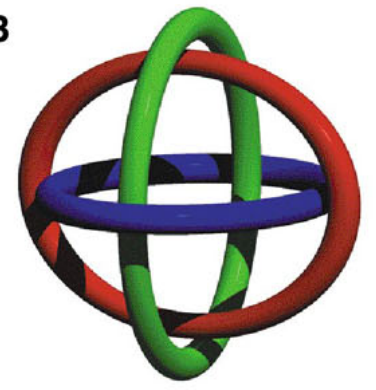

C

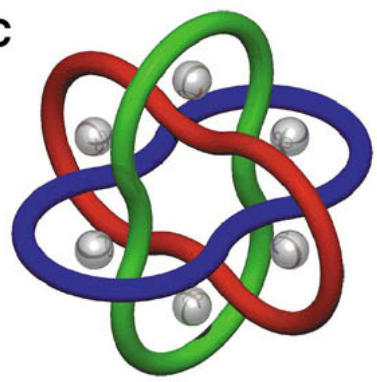

D



Exo-Tridentate



Transition Metals

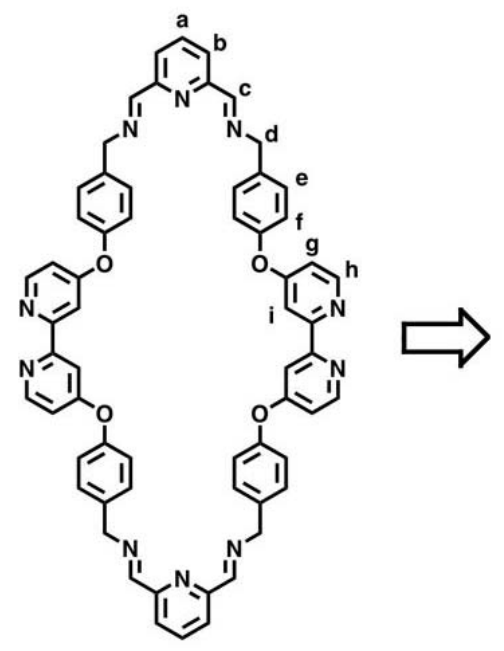

$\sqrt{ }$

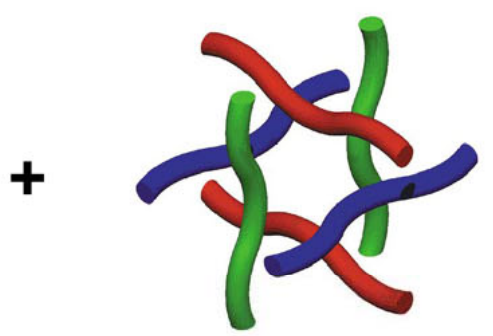

\section{Endo-Bidentate}

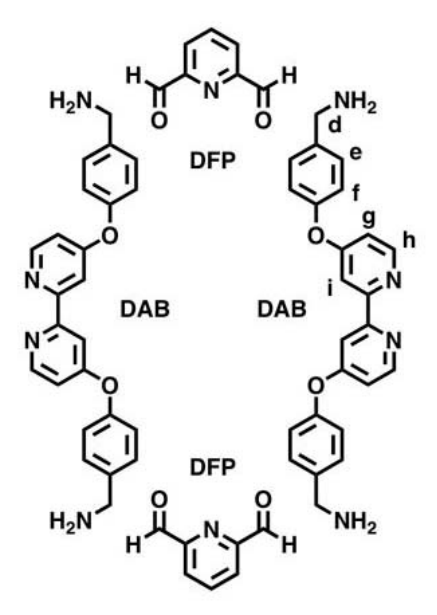


Fig. 2

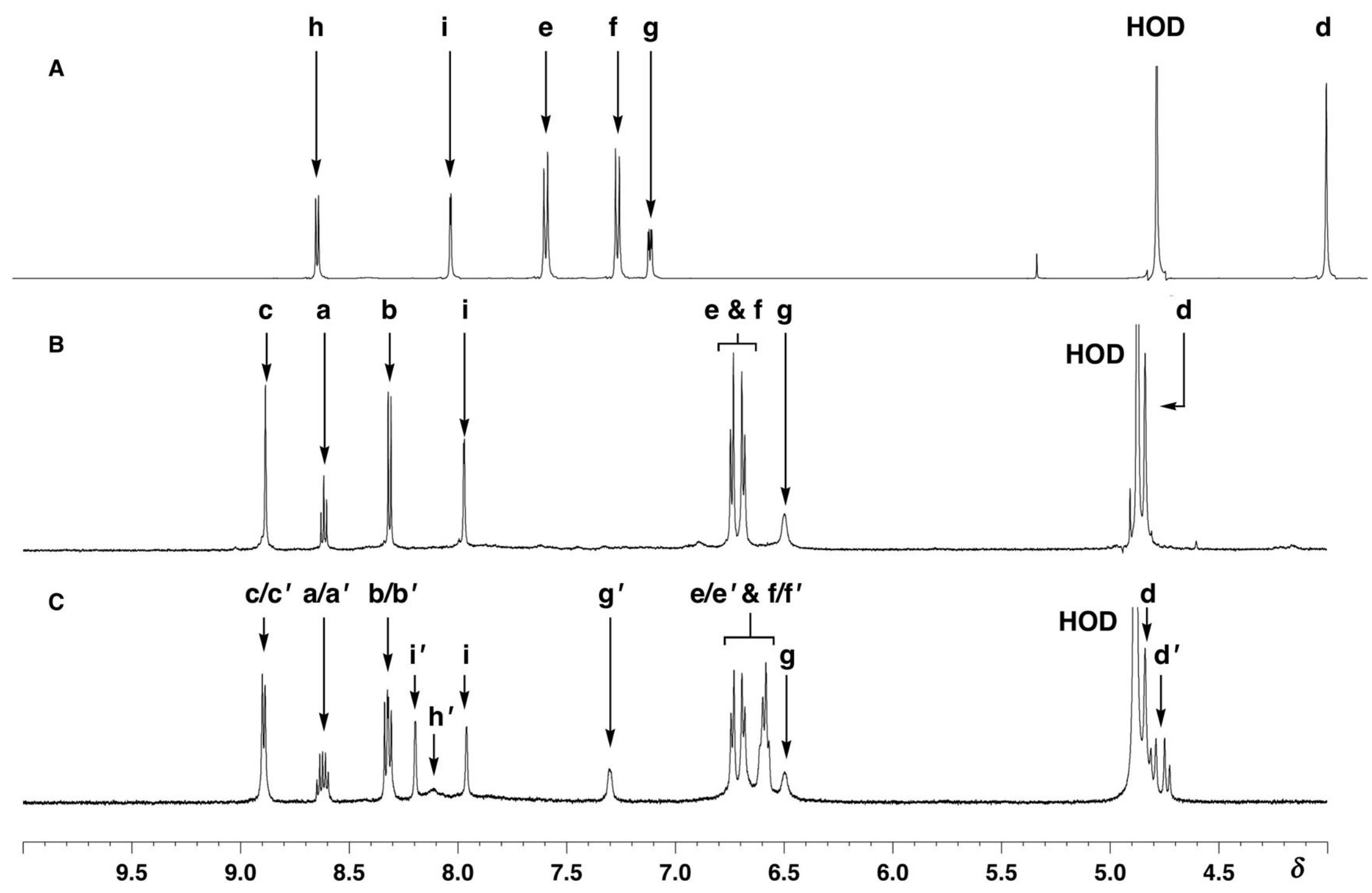


Fig. 3

A
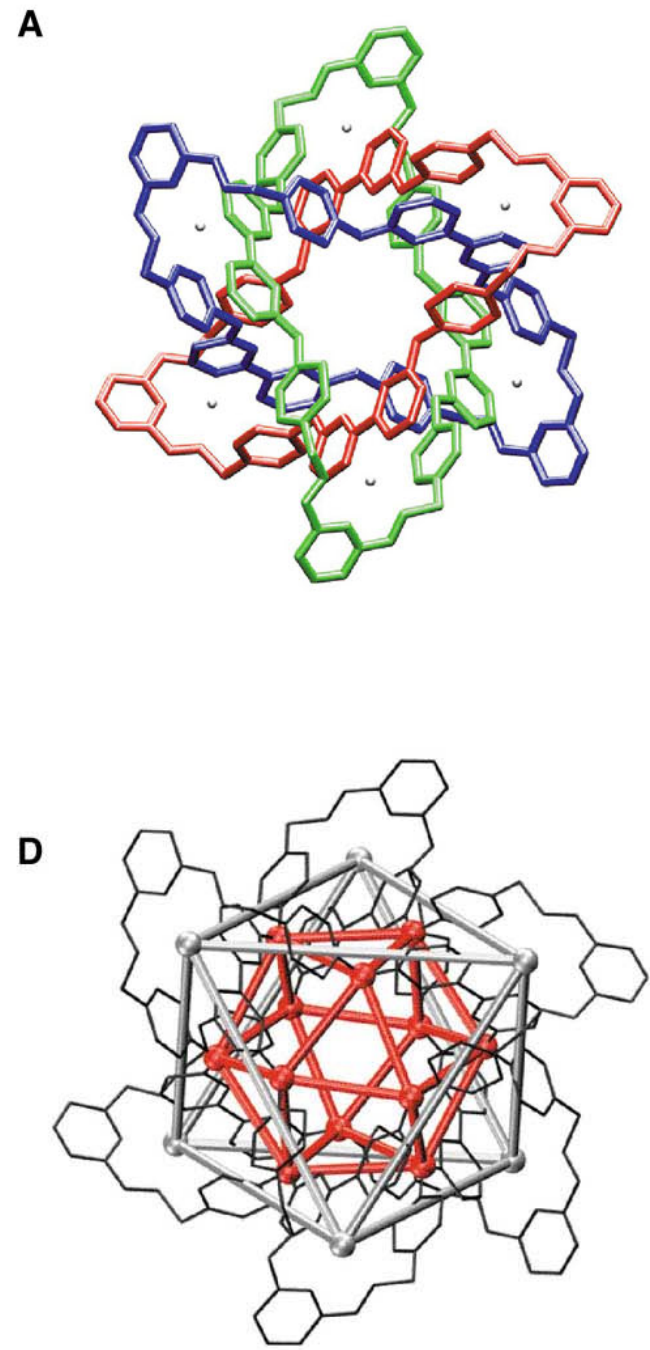

B
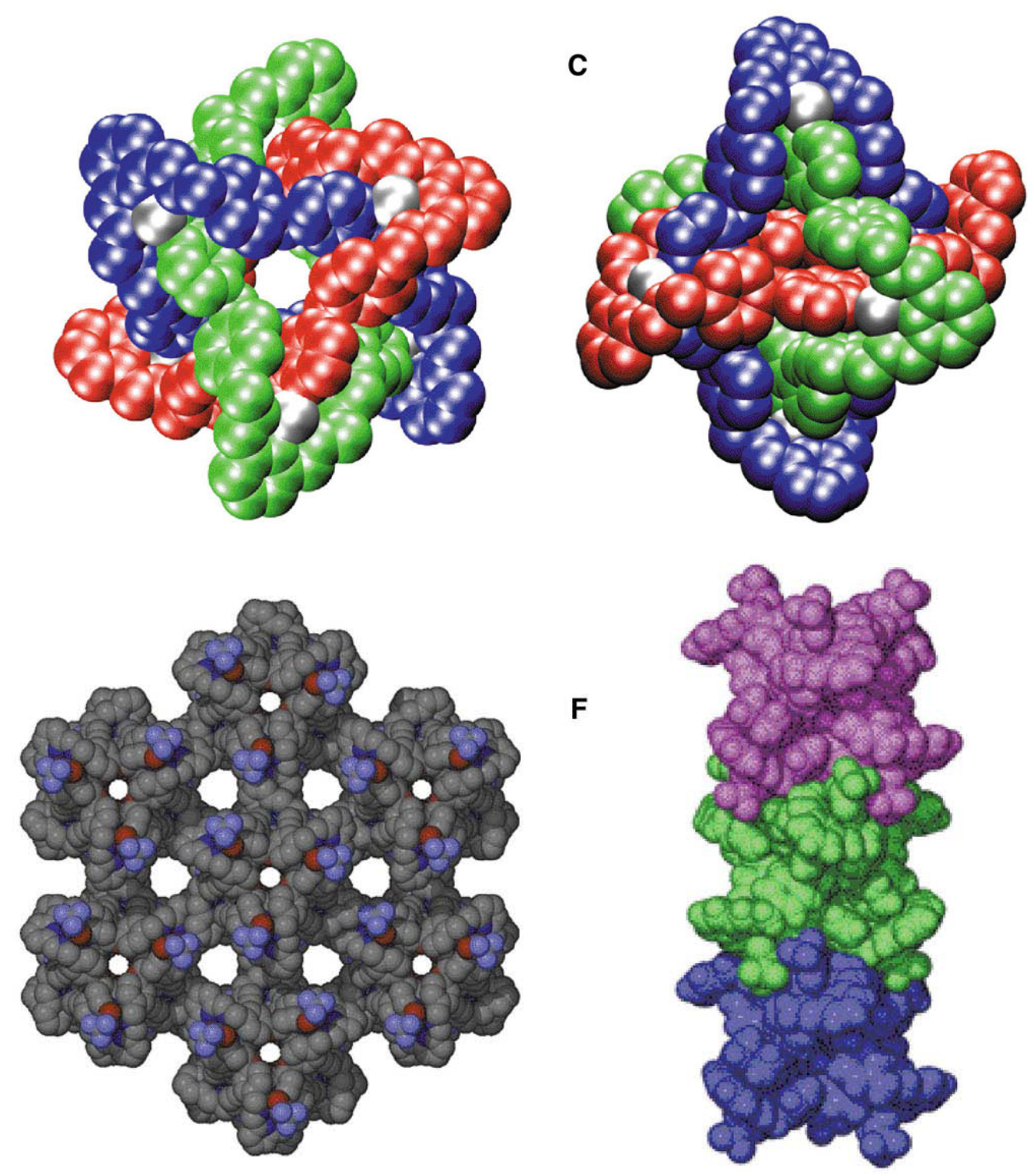
Fig. 4

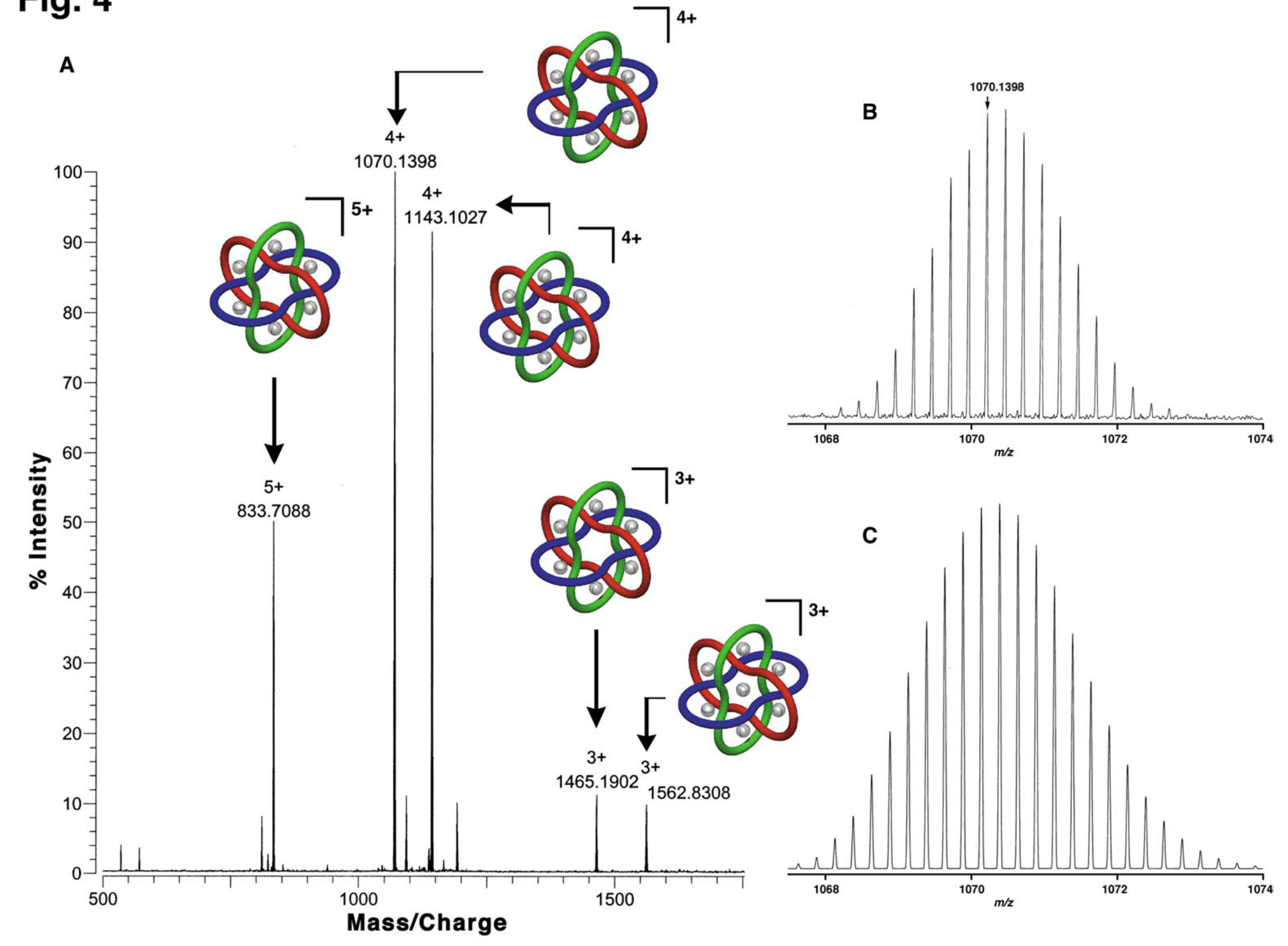




\section{Molecular Borromean Rings}

- by K. S. Chichak, S. J. Cantrill, A. R. Pease, S.-H. Chiu, G. W. V. Cave, J. L. Atwood, and J. F. Stoddart

Here is a first offering of graphic art for consideration for the cover.

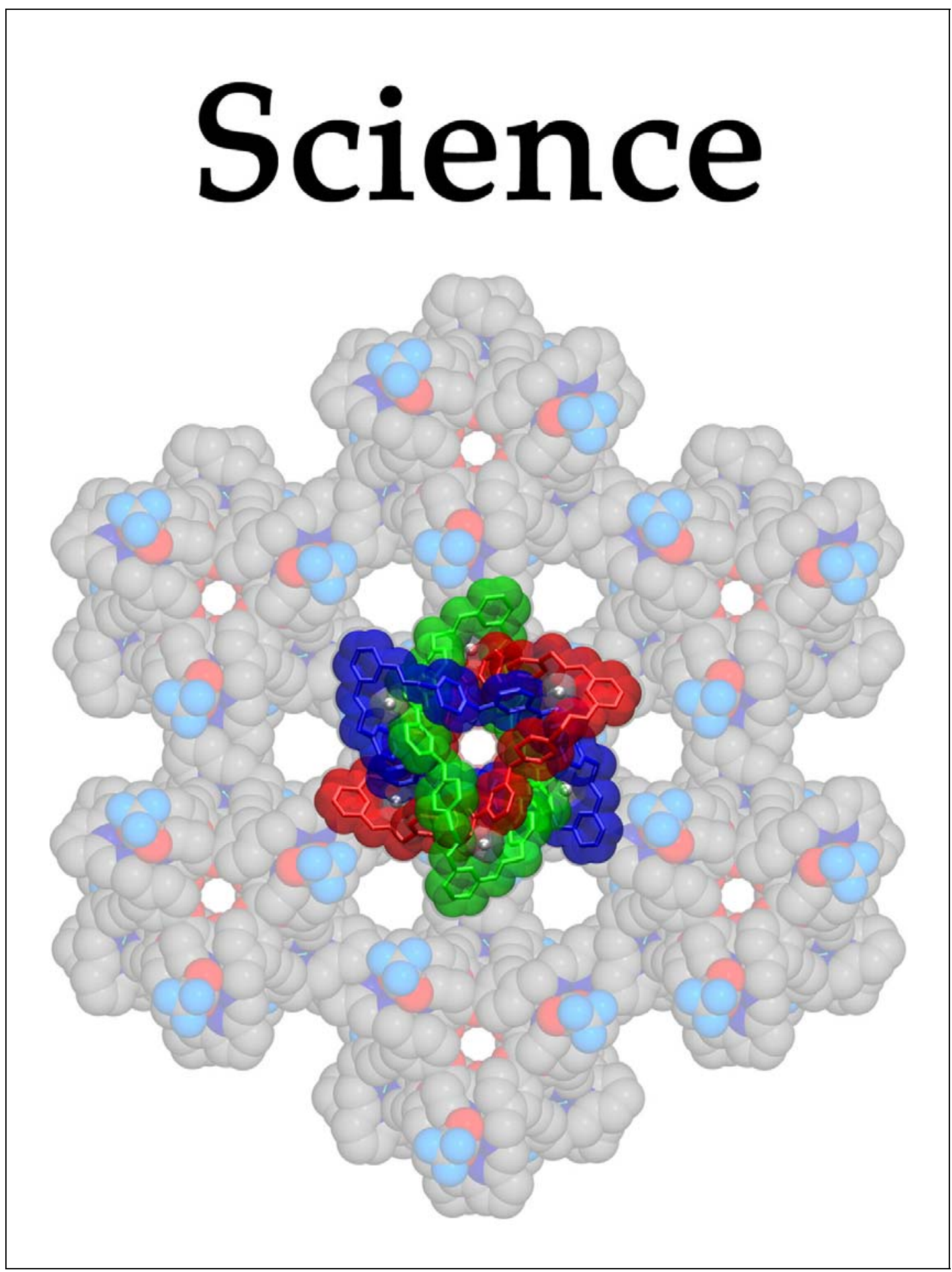




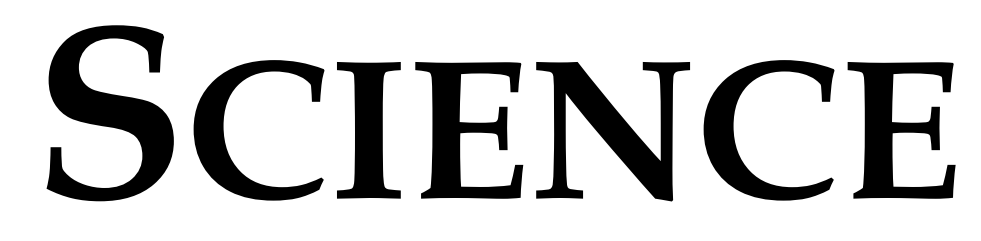

\title{
Molecular Borromean Rings
}

\author{
Kelly S. Chichak, ${ }^{1}$ Stuart J. Cantrill, ${ }^{1}$ Anthony R. Pease, ${ }^{1}$ \\ Sheng-Hsien Chiu, ${ }^{1}$ Gareth W. V. Cave, ${ }^{2}$ Jerry L. Atwood, ${ }^{2}$
}

J. Fraser Stoddart ${ }^{1 *}$

\section{SUPPORTING INFORMATION}

${ }^{1}$ Department of Chemistry and Biochemistry and the California NanoSystems Institute, University of California, Los Angeles, 405 Hilgard Avenue, Los Angeles, CA 90095, USA. ${ }^{2}$ Department of Chemistry, University of Missouri-Columbia, MO 65211, USA.

*To whom correspondence should be addressed. E-Mail: stoddart@chem.ucla.edu 


\section{Synthesis and Characterization}

The diamine DAB containing the bipyridyl ligand was obtained (Scheme S1) as its $4 \mathrm{CF}_{3} \mathrm{CO}_{2}{ }^{-}$salt $\mathbf{D A B}-\mathrm{H}_{4} \cdot 4 \mathrm{TFA}$ in five steps starting from 4-methoxybenzylamine. Nucleophilic cleavage of the methyl ether in refluxing $48 \% \mathrm{HBr}$ afforded (92\%) the hydrobromide $1-\mathrm{H} \cdot \mathrm{Br}$ of 4-hydroxybenzylamine. When this salt was treated with 1.1 equivalents of $(t \text {-Boc })_{2} \mathrm{O}$ in a methanolic suspension of $\mathrm{NaHCO}_{3}$, the $t$-butyloxycarbonyl-protected amine 2 was isolated in 93\% yield. In the meantime, the bipyridyl$N, N^{\prime}$-dioxide 3 was prepared by the treatment of $4,4^{\prime}$-dinitro-2,2'-bipyridyl- $N, N^{\prime}$-dioxide (S1) with the sodium salt of 2 in anhydrous DMF at $50{ }^{\circ} \mathrm{C}$. Compound 4 was produced $(93 \%)$ by the catalytic transfer hydrogenation of 3 using $10 \% \mathrm{Pd} / \mathrm{C}$ with $\mathrm{NaH}_{2} \mathrm{PO}_{2}$ as the source of $\mathrm{H}_{2}$ in a mixture of $\mathrm{EtOH} / \mathrm{AcOH}$ under mild conditions. In the final step, DAB- $\mathrm{H}_{4} \cdot 4$ TFA was isolated in almost quantitative yield following $t$-Boc deprotection using $\mathrm{CF}_{3} \mathrm{CO}_{2} \mathrm{H}$ in $\mathrm{CH}_{2} \mathrm{Cl}_{2}$. Depending on whether $\mathrm{MeOH}$ or $95 \% \mathrm{EtOH}$ are employed as solvent in reactions between equimolar amounts of DFP, DAB- $\mathrm{H}_{4} \cdot 4 \mathrm{TFA}$, and $\mathrm{Zn}(\mathrm{OAc})_{2}$, two outcomes prevail-(i) one in $\mathrm{MeOH}$, where a single product (BR) containing six $\mathrm{Zn}(\mathrm{II})$ ions is isolated and (ii) in $95 \% \mathrm{EtOH}$ where two inseparable products, one $(\mathbf{B R})$ containing six $\mathrm{Zn}(\mathrm{II})$ ions as before, and the other (Zn@BR) containing seven $\mathrm{Zn}(\mathrm{II})$ ions - as indicated by ${ }^{1} \mathrm{H}$ NMR spectroscopy and ESI mass spectrometry (see Fig. 2 and Fig. 4 in the article itself).

\section{Materials and Methods}

All solvents (EM Science) were dried prior to use according to literature procedures. 95\% Ethanol (Pharmco) and deuterated solvents (Cambridge Isotope Laboratories) for NMR spectroscopic analyses were used as received. All reagents and starting materials, including 2,6-diformylpyridine (DFP), were purchased from Aldrich and used without further purification. 4,4'-Dinitro-2,2'-bipyridyl- $N, N^{\prime}$-dioxide was synthesized according to a known literature procedure (S1). Thin-layer chromatography (TLC) was performed either on aluminum sheets coated with silica-gel 60F (Merck 5554) or on aluminum sheets coated with aluminum oxide 60F (Merck 5550/7, neutral). The plates were inspected by UV light. Column chromatography was carried out, either by using silicagel 60 (Merck 9358, 230-400 mesh) or by using aluminum oxide (Aldrich, 150 mesh, neutral, activity II). Melting points were determined on an Electrothermal 9100 melting-point apparatus and are uncorrected. All ${ }^{1} \mathrm{H}$ and ${ }^{13} \mathrm{C}$ NMR spectra were recorded on either a Bruker Avance600 (600 MHz and $150 \mathrm{MHz}$, respectively), Bruker 
Avance500 (500 MHz and $125 \mathrm{MHz}$, respectively), or Bruker ARX500 (500 MHz and 125 $\mathrm{MHz}$, respectively). All chemical shifts are quoted in ppm, relative to tetramethylsilane, using the residual solvent peak as a reference standard. Mass spectra were measured on an IonSpec 7.0T Ultima FTMS with MALDI and ESI ion sources. MALDI Mass spectra were obtained using dihydroxybenzoic acid as the supporting matrix. Electrospray mass spectra were obtained with either $\mathrm{MeOH}$ or $\mathrm{MeCN}$ as the liquid carrier.

1-H Br: The following procedure is a modified one based on that reported (S2) in the patent literature. When 4-methoxybenzylamine $(11.6 \mathrm{~g}$, $84.6 \mathrm{mmol})$ was added with stirring to $48 \% \mathrm{HBr}(30 \mathrm{~mL})$, a precipitate was formed. Since an extremely exothermic reaction ensues, the addition was done very slowly. The mixture was then stirred under reflux for $6 \mathrm{~h}$, before being cooled down to room temperature and concentrated to dryness, giving a light pink solid. $\mathrm{MeCN}(20 \mathrm{~mL})$ was added to this residue and the product 1-H $\cdot \mathrm{Br}$ was collected by filtration and dried under vacuum. Yield: $16.2 \mathrm{~g}, 92 \%$. The product was identified by ${ }^{1} \mathrm{H}$ NMR spectroscopy and then employed in the next step without further purification. ${ }^{1} \mathrm{H}$ NMR $\left(500 \mathrm{MHz}, \mathrm{D}_{2} \mathrm{O}, 25^{\circ} \mathrm{C}\right): \delta=3.95(\mathrm{~s}, 2 \mathrm{H}), 6.79$ $(\mathrm{d}, J=8.6 \mathrm{~Hz}, 2 \mathrm{H}), 7.19(\mathrm{~d}, J=8.6 \mathrm{~Hz}, 2 \mathrm{H})$.

2: Di-tert-butyl dicarbonate $(18.5 \mathrm{~g}, 84.8 \mathrm{mmol})$ was added with stirring under an atmosphere of argon to a solution of $1-\mathrm{H} \cdot \mathrm{Br}(16.0 \mathrm{~g}, 78.4 \mathrm{mmol})$ and $\mathrm{NaHCO}_{3}(26.3 \mathrm{~g}$, $313 \mathrm{mmol})$ in $\mathrm{MeOH}(200 \mathrm{~mL})$ at room temperature. After stirring the reaction mixture for $24 \mathrm{~h}$, it was filtered to remove excess of $\mathrm{NaHCO}_{3}$. The solvents were removed under reduced pressure and the oily residue was purified by column chromatography $\left[\mathrm{SiO}_{2}\right.$ : EtOAc/hexanes (1:4)] to afford 2 as a yellow oil. Yield: $16.2 \mathrm{~g}, 93 \% .{ }^{1} \mathrm{H}$ NMR $(500 \mathrm{MHz}$, $\left.\mathrm{CD}_{2} \mathrm{Cl}_{2}, 25^{\circ} \mathrm{C}\right): \delta=1.46(\mathrm{~s}, 9 \mathrm{H}), 4.19(\mathrm{~d}, J=5.5 \mathrm{~Hz}, 2 \mathrm{H}), 5.09(\mathrm{bs}, 1 \mathrm{H}), 6.77(\mathrm{~d}, J=8.5 \mathrm{~Hz}$, $2 \mathrm{H}), 6.96(\mathrm{bs}, 1 \mathrm{H}), 7.09(\mathrm{~d}, J=8.1 \mathrm{~Hz}, 2 \mathrm{H}) ;{ }^{13} \mathrm{C} \mathrm{NMR}\left(125 \mathrm{MHz}, \mathrm{CD}_{2} \mathrm{Cl}_{2}, 25^{\circ} \mathrm{C}\right): \delta=28.5$, 44.4, 115.8, 129.1, 130.8, 156.0; HRMS (MALDI): $\mathrm{m} / z 246.1100[\mathrm{M}+\mathrm{Na}]^{+}$.

3: Solid $\mathrm{NaH}(550 \mathrm{mg}, 22.8 \mathrm{mmol}$ ) was added in small portions (each addition was made after the evolution of gases subsided) to a stirred solution of $2(4.69 \mathrm{~g}, 21.0 \mathrm{mmol})$ in DMF $(10 \mathrm{ml})$ under an argon atmosphere. 4,4'-Dinitro-2,2'-bipyridyl- $N, N^{\prime}$-dioxide $(2.54 \mathrm{~g}, 9.13 \mathrm{mmol})$ was added to this solution and the resulting brown reaction mixture was heated at $50{ }^{\circ} \mathrm{C}$ for $4 \mathrm{~h}$. Thereafter, the solution was cooled down to room temperature and poured into $\mathrm{H}_{2} \mathrm{O}(250 \mathrm{~mL})$ before being extracted with EtOAc $(3 \times 125$ $\mathrm{mL})$ and once with $\mathrm{CH}_{2} \mathrm{Cl}_{2}(100 \mathrm{~mL})$. The combined organic extracts were then washed 
with water $(3 \times 125 \mathrm{~mL})$, brine $(125 \mathrm{~mL})$, and dried over $\mathrm{Na}_{2} \mathrm{SO}_{4}$. The solvents were removed under reduced pressure to give an orange-colored product which was recrystallized from EtOAc, affording 3 as light orange plates. Yield: $3.71 \mathrm{~g}, 64 \%$. M.p. 217-218 ${ }^{\circ} \mathrm{C}$; ${ }^{1} \mathrm{H}$ NMR $\left(500 \mathrm{MHz}, \mathrm{CD}_{2} \mathrm{Cl}_{2}, 25^{\circ} \mathrm{C}\right): \delta=1.44(\mathrm{~s}, 18 \mathrm{H}), 4.08(\mathrm{~d}, J=5.8 \mathrm{~Hz}, 4 \mathrm{H})$, $5.12(\mathrm{bs}, 2 \mathrm{H}), 6.92(\mathrm{dd}, J=3.5,7.3 \mathrm{~Hz}, 2 \mathrm{H}), 7.08(\mathrm{~d}, J=8.5 \mathrm{~Hz}, 4 \mathrm{H}), 7.15(\mathrm{~d}, J=3.5 \mathrm{~Hz}$, $2 \mathrm{H}), 7.34(\mathrm{~d}, J=8.5 \mathrm{~Hz}, 4 \mathrm{H}), 8.12(\mathrm{~d}, J=7.3 \mathrm{~Hz}, 2 \mathrm{H}) ;{ }^{13} \mathrm{C} \mathrm{NMR}\left(125 \mathrm{MHz}, \mathrm{CD}_{2} \mathrm{Cl}_{2}, 25^{\circ} \mathrm{C}\right)$ : $\delta=28.5,44.1,115.8,116.6,120.8,129.6,137.5,141.1,143.0,153.7,155.2$; HRMS (MALDI): $\mathrm{m} / \mathrm{z} 631.2762[\mathrm{M}+\mathrm{H}]^{+}$.

4: The following procedure is a modified one based on that reported (S3) for the deoxygenation of 2,2'-bipyridyl- $N, N^{\prime}$-dioxide. An excess of $\mathrm{NaH}_{2} \mathrm{PO}_{2}(4.28 \mathrm{~g}, 47.6$ mmol) was added in one portion to a three-necked flask equipped with a condenser containing a stirred suspension of 3 (3.00 g, $4.76 \mathrm{mmol})$ and 10\% Pd/C (1.00 g) in 75/15 $\mathrm{EtOH} / \mathrm{AcOH}(90 \mathrm{~mL})$. The reaction flask was sealed with a balloon to prevent the loss of the $\mathrm{H}_{2}$ gas which evolves from the decomposition of $\mathrm{NaH}_{2} \mathrm{PO}_{2}$ and the mixture was heated at $70{ }^{\circ} \mathrm{C}$ for $15 \mathrm{~h}$. The reaction mixture was then cooled down to room temperature and filtered through Celite. The filter cake was washed with $\mathrm{CH}_{2} \mathrm{Cl}_{2}(3 \times$ $100 \mathrm{~mL}$ ). The filtrates were combined and the volume was concentrated to $50 \mathrm{~mL}$ under reduced pressure, giving a light yellow solution. The $\mathrm{AcOH}$ was neutralized by adding solid $\mathrm{NaHCO}_{3}(6 \mathrm{~g})$ in $\mathrm{H}_{2} \mathrm{O}(50 \mathrm{~mL})$. The solution was concentrated to dryness, producing a beige product which was suspended in $\mathrm{H}_{2} \mathrm{O}$, collected by filtration, washed with $\mathrm{H}_{2} \mathrm{O}$, and dried. Yield: $2.62 \mathrm{~g}$, $93 \%$. The crude product was recrystallized from EtOAc/hexanes, affording 4 as fine white needles. Yield: 2.21 g, 78\%. M.p. 158$160{ }^{\circ} \mathrm{C} ;{ }^{1} \mathrm{H}$ NMR $\left(500 \mathrm{MHz}, \mathrm{CD}_{2} \mathrm{Cl}_{2}, 25^{\circ} \mathrm{C}\right): \delta=1.45(\mathrm{~s}, 18 \mathrm{H}), 4.33(\mathrm{~d}, J=7.1 \mathrm{~Hz}, 4 \mathrm{H}), 5.04$ (bs, 2H), $6.86(\mathrm{dd}, J=3.5,7.3 \mathrm{~Hz}, 2 \mathrm{H}), 7.11(\mathrm{~d}, J=8.5 \mathrm{~Hz}, 4 \mathrm{H}), 7.37(\mathrm{~d}, J=8.5 \mathrm{~Hz}, 4 \mathrm{H})$, $7.92(\mathrm{~d}, J=3.5 \mathrm{~Hz}, 2 \mathrm{H}), 8.44(\mathrm{~d}, J=7.3 \mathrm{~Hz}, 2 \mathrm{H}) ;{ }^{13} \mathrm{C} \mathrm{NMR}\left(125 \mathrm{MHz}, \mathrm{CD}_{2} \mathrm{Cl}_{2}, 25{ }^{\circ} \mathrm{C}\right): \delta=$ 28.5, 44.2, 109.3, 112.9, 121.2, 129.5, 137.0, 151.0, 153.7, 158.1, 166.1; HRMS (MALDI): $\mathrm{m} / \mathrm{z}$ $621.2684[\mathrm{M}+\mathrm{Na}]^{+}$.

DAB- $\mathrm{H}_{4}$ 4TFA: The Boc protecting groups in 4 were removed by the addition of $\mathrm{CF}_{3} \mathrm{CO}_{2} \mathrm{H}(4 \mathrm{~mL})$ to a solution of $4(1.00 \mathrm{~g}, 1.67 \mathrm{mmol})$ in $\mathrm{CH}_{2} \mathrm{Cl}_{2}(50 \mathrm{~mL})$ with stirring at room temperature for $48 \mathrm{~h}$. The reaction mixture was concentrated to dryness, leaving a sticky residue. The excess of $\mathrm{CF}_{3} \mathrm{CO}_{2} \mathrm{H}$ was removed by three repeated additions and removals of $\mathrm{MeOH}(20 \mathrm{~mL})$ by rotary evaporation under reduced pressure at $50{ }^{\circ} \mathrm{C}$, leaving a pink sticky residue. This residue was treated with $\mathrm{CH}_{2} \mathrm{Cl}_{2}$ and the solvent was removed by rotary evaporation under reduced pressure at $40{ }^{\circ} \mathrm{C}$ until a light pink 
amorphous solid remained that is moisture sensitive. It was employed as one of the starting materials in the next step without further purification. Yield of crude DAB$\mathrm{H}_{4}$ 4TFA: $1.32 \mathrm{~g}$, 95\%; ${ }^{1} \mathrm{H}$ NMR (500 MHz, $\left.\mathrm{CD}_{3} \mathrm{OD}, 25^{\circ} \mathrm{C}\right): \delta=4.20(\mathrm{~s}, 4 \mathrm{H}), 7.18(\mathrm{dd}, J=$ 3.5, $7.3 \mathrm{~Hz}, 2 \mathrm{H}), 7.33(\mathrm{~d}, J=8.5 \mathrm{~Hz}, 4 \mathrm{H}), 7.64(\mathrm{~d}, J=8.5 \mathrm{~Hz}, 4 \mathrm{H}), 8.06(\mathrm{~d}, J=3.5 \mathrm{~Hz}, 2 \mathrm{H})$, $8.66(\mathrm{~d}, J=7.3 \mathrm{~Hz}, 2 \mathrm{H}) ;{ }^{13} \mathrm{C} \mathrm{NMR}\left(125 \mathrm{MHz}, \mathrm{CD}_{3} \mathrm{OD}, 25^{\circ} \mathrm{C}\right): \delta=43.6,112.8,114.8,117.9$ (q, $J=291 \mathrm{~Hz}, \mathrm{TFA}), 122.6,132.8,133.0,149.8,152.2,155.2,162.3(\mathrm{q}, J=35.5 \mathrm{~Hz}, \mathrm{TFA})$ 170.0; HRMS (ESI): $m / z$ (\%) 399.1836 (100) $\left[\mathrm{M}-4 \mathrm{CF}_{3} \mathrm{CO}_{2} \mathrm{H}+\mathrm{H}\right]^{+}, 819.3428$ (62) [2M$\left.8 \mathrm{CF}_{3} \mathrm{CO}_{2} \mathrm{H}+\mathrm{Na}\right]^{+}$.

BR 12TFA and Zn@BR 14TFA: The reaction to make the Borromean links was carried out in both reagent grade $\mathrm{MeOH}$ and $95 \% \mathrm{EtOH}$. Hence, the solvent in the procedure will be referred to as an alcohol. $\mathrm{Zn}(\mathrm{OAc})_{2}(32.9 \mathrm{mg}, 0.179 \mathrm{mmol})$ was added to a stirred alcoholic solution (15 mL) containing DAB- $\mathrm{H}_{4}$ 4TFA (153 mg, $\left.0.179 \mathrm{mmol}\right)$ and DFP (24.2 $\mathrm{mg}, 0.179 \mathrm{mmol}$ ) and the reaction mixture was heated under reflux for $36 \mathrm{~h}$ producing a pale yellow colored solution. The solvents were removed by rotary evaporation under reduced pressure at $50{ }^{\circ} \mathrm{C}$, leaving pale yellow-colored products. The crude products were purified by recrystallization from a $\mathrm{MeOH}(2 \mathrm{~mL})$ solution into which $\mathrm{Et}_{2} \mathrm{O}$ was allowed to diffuse slowly. Yield of BR 12TFA from the reaction in MeOH solution: $110 \mathrm{mg}$, 78\%; ${ }^{1} \mathrm{H}$ NMR $\left(600 \mathrm{MHz}, \mathrm{CD}_{3} \mathrm{OD}, 25^{\circ} \mathrm{C}\right): \delta=4.84(\mathrm{~s}, 24 \mathrm{H})$, $6.50(\mathrm{bs}, 12 \mathrm{H}), 6.68(\mathrm{~d}, J=8.4 \mathrm{~Hz}, 24 \mathrm{H}), 6.74(\mathrm{~d}, J=8.4 \mathrm{~Hz}, 12 \mathrm{H}), 7.97(\mathrm{~d}, J=2.4 \mathrm{~Hz}, 12 \mathrm{H})$, $8.31(\mathrm{~d}, J=7.8 \mathrm{~Hz}, 24 \mathrm{H}), 8.62(\mathrm{~d}, J=7.8 \mathrm{~Hz}, 12 \mathrm{H}), 8.89(\mathrm{~s}, 12 \mathrm{H}) ;{ }^{13} \mathrm{C}$ NMR $(150 \mathrm{MHz}$, $\left.\mathrm{CD}_{3} \mathrm{OD}, 25^{\circ} \mathrm{C}\right) 15$ of 16 signals: $\delta=63.1,112.6,113.9,117.9$ (q, $\left.J=296 \mathrm{~Hz}, \mathrm{TFA}\right), 122.3$, 130.8, 131.2, 135.1, 145.5, 148.2, 151.7, 153.3, 162.0, 162.5 (q, $J=34.6 \mathrm{~Hz}, \mathrm{TFA}) 169.8$; HRMS (ESI): $m / z \quad(\%) \quad 1465.1902$ (10) $\left[M-3 \mathrm{CF}_{3} \mathrm{CO}_{2}\right]^{3+}, 1070.1398$ (100) $\quad[M+\mathrm{Zn}-$ $\left.4 \mathrm{CF}_{3} \mathrm{CO}_{2}\right]^{4+}, 833.7088(50)\left[\mathrm{M}-5 \mathrm{CF}_{3} \mathrm{CO}_{2}\right]^{5+}$. Yield of BR $12 \mathrm{TFA}$ and Zn@BR $14 \mathrm{TFA}$ in admixture from the reaction in $95 \% \mathrm{EtOH}: 92 \mathrm{mg}, 65 \%$. For the ${ }^{1} \mathrm{H}$ NMR spectra and ESI mass spectra of BR 12TFA plus Zn@BR 14TFA, see Fig. 2 and Fig. 4 in the article.

\section{References and Notes}

S1 S. Anderson, E. C. Constable, K. R. Seddon, J. E. Turp, J. E. Baggot, M. J. Pilling, J. Chem. Soc., Dalton Trans. 2247 (1985).

S2 V. Rossetti, A. Dondoni, G. Fantin, EP 8312266 (1983).

S3 R. Balicki, L. Kaczkarek, Gazz. Chim. Ital. 124, 385-386 (1994). 

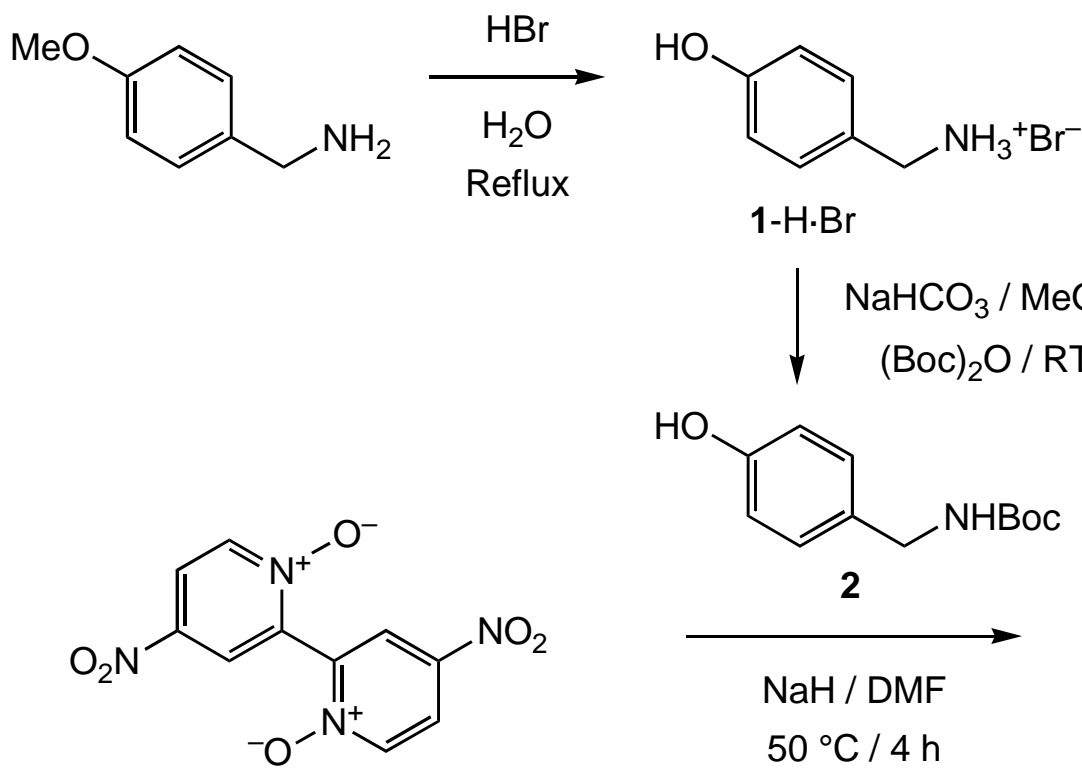

\section{Scheme S1}

$1-\mathrm{H} \cdot \mathrm{B}$

$\downarrow \begin{gathered}\mathrm{NaHCO}_{3} / \mathrm{MeOH} \\ (\mathrm{Boc})_{2} \mathrm{O} / \mathrm{RT}\end{gathered}$

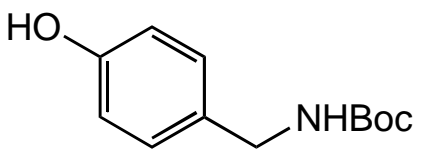

$\mathrm{NaH} / \mathrm{DMF}$

$50{ }^{\circ} \mathrm{C} / 4 \mathrm{~h}$

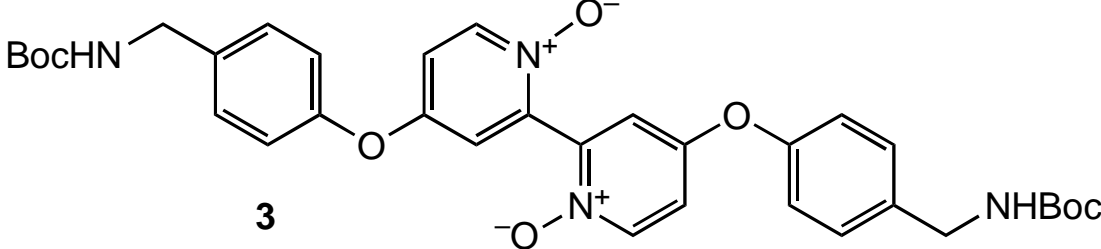

$\mathrm{NaH}_{2} \mathrm{PO}_{2}$

$\mathrm{Pd} / \mathrm{C} / \mathrm{EtOH} / \mathrm{AcOH}$
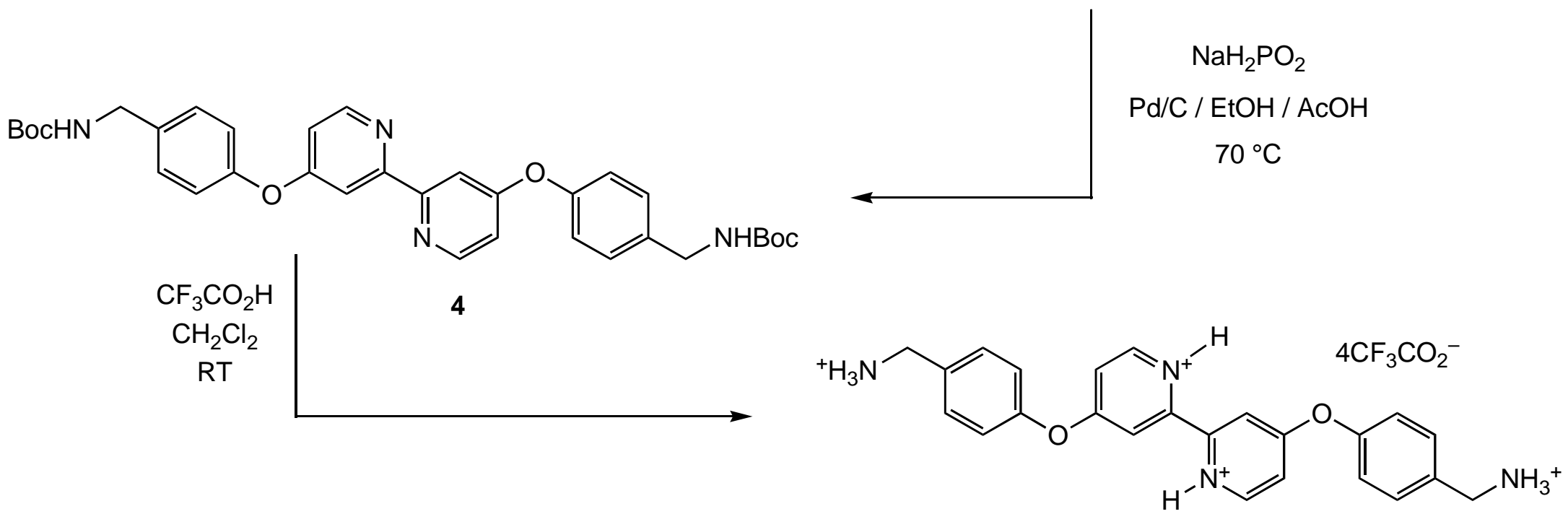

DAB- $\mathrm{H}_{4} \cdot 4 T F A$ 